\title{
Family medicine again dominates unfilled positions in residency match
}

\author{
- Cite as: CMAJ 2019 March 18;191:E322. doi: 10.1503/cmaj.109-5727
}

Posted on cmajnews.com on Feb. 28, 2019.

$\mathrm{T}$ here are 209 unfilled positions after the first iteration of the 2019 R-1 Main Residency Match, and family medicine accounts for more than half.

According to the Canadian Residency Matching Service (CaRMS), 138 family medicine spots were not filled. The University of Ottawa, alone, had 31 of those positions. The University of Saskatchewan failed to fill 15 family medicine residency slots, followed by the University of Calgary with 11.

Medical schools in Quebec (Université Laval, Université de Sherbrooke, Université de Montréal, and McGill University) combined for 41 unfilled family medicine spots.

"It worries me that so many family medicine spots went unfilled," Dr. Nadia Alam, president of the Ontario Medical Association, said on Twitter. "It suggests a dropping interest in family medicine and that's a big problem. More family docs means a healthier population."

Many doctors, residents and medical students took to social media to congratulate students who matched and encourage those who will have to try again in the next iteration. "Didn't match? I have many success stories from once unmatched candidates ... including me! CaRMS is not a perfect process," wrote Dr. Alexi Millman, a urology resident in Toronto.

Although many trainees may be "overjoyed" after the match, "a lot of amazing medical students are left feeling disappointed and dejected. Let's be sensitive, kind and supportive to one another," added medical student Mei W. Wen.

Dr. Gigi Osler, president of the Canadian Medical Association (CMA), noted that the CMA supports medical students

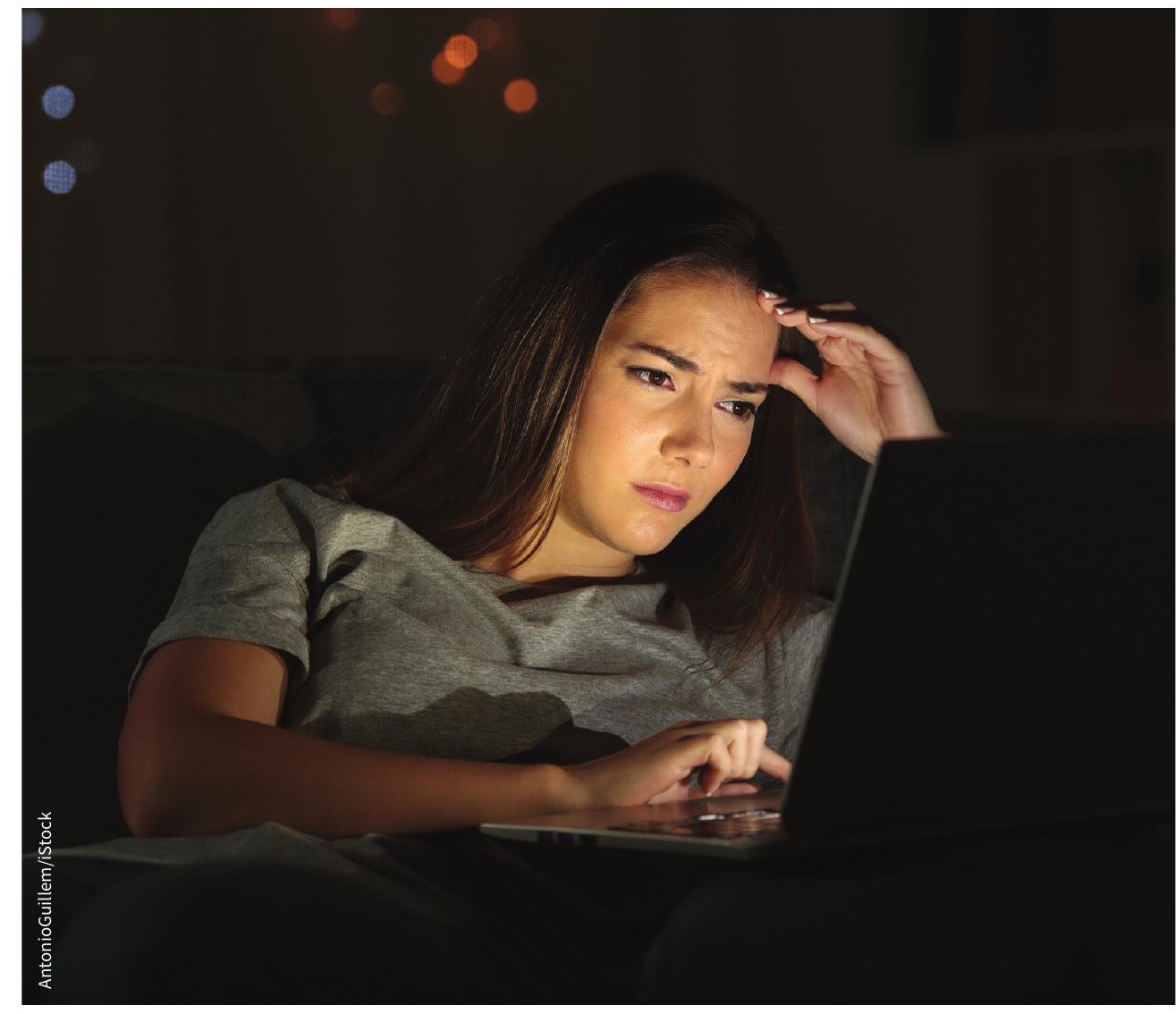

Logging in to see if they matched for residency positions ends in disappointment for some medical students.

and residents, and recognizes the "importance of creating additional residency spots." The CMA will continue to advocate for more funding for additional postgraduate training spaces, added Osler.

The Canadian Federation of Medical Students (CFMS) reminded unmatched students that they "are not alone" and pointed them to resources to help them continue on their journeys to becoming successful physicians. Some of these resources include wellness supports, the
CFMS unmatched peer mentorship network, a second-round application reimbursement of $\$ 150$, and the CFMS matchbook with advice for unmatched students.

Last year, there were 228 unfilled positions after the first iteration. Of those, 152 were family medicine spots. Most unfilled family medicine positions in the 2018 match were at the Quebec medical schools, with a total of 96 .

Roger Collier, CMAJ 